\title{
A Gender Mirrored Framework into Suicidal Ideation and Associated Risk Factors
}

\author{
Bose Makinde ${ }^{1,2^{*}}$, Ayodele Adeoye ${ }^{3}$ \\ ${ }^{1}$ Ph.D in Social Work by Research, Texila American University, Nigeria \\ ${ }^{2}$ Department of Social Work \& Human Services, Babcock University, Ilishan Remo, Ogun \\ State, Nigeria \\ ${ }^{3}$ Department of Education and Humanities, Babcock University, Ilishan Remo, Ogun State
}

Nigeria

\begin{abstract}
The study assessed a gender mirrored framework into suicidal ideation and associated risk factors among undergraduates amid the prevalence of suicide ideation. A cross-sectional design was adopted for this study. The sample size was 993 respondents selected from undergraduates in public and private universities. The Statistical package for social science (SPSS) version 23 was utilized in analyzing the data from this study. Four null hypotheses on gender, suicide ideation, and four psychosocial risk factors (depression, childhood adversity, economic recession, and media reporting) were raised and tested at a 0.05 level of significance. The results revealed a highly significant correlation between gender and suicide ideation. Childhood adversity is associated with gender $(r=-$ .149, $p$ >0.01). The relationship between gender, suicidation, and economic recession was also significant. The study recommended that gender-specific suicide prevention and intervention programme should be provided by institutions of higher learning and the creation of awareness on the effect of childhood experience on the latter psychological health of a person.
\end{abstract}

Keywords: Childhood Adversity, Depression, Economic Recession, Gender, Media Reporting, Suicide Ideation.

\section{Introduction}

Suicidal ideation, which is also known as suicidal thought, is becoming an alarming social problem. Most importantly, among the students, with Nigerian students having one of the highest rates of suicidal ideation [1], and university students in Africa have been identified with a higher level of suicidal ideation [2].

Suicidal thoughts, also known as suicidal ideation, are considered to be an important precursor to suicide [3]. [4], reports that suicidal ideation is what leads to suicide. Suicidal ideation also has a strong connection with suicide attempt, [5] findings have emphasized the severity of suicidal ideation, with $50 \%$ of planned suicide attempts occurring within one year of suicidal ideation.

However, numerous factors lead to a person having suicidal ideation [6]. There must have been unpleasant situations because human beings naturally do not want to die. [7] affirms that continuous suicide ideation comes when an individual is going through challenges which they consider unbearable and are looking for an outlet.

For the purpose of this study, the factors for consideration are depression, childhood adversity, economic recession, and media reporting. [8] confirm that depression has become worrisome on college campuses. In addition, depression has been noted as a 
suicidal ideation risk factor among university students [9]. So much so that suicidal ideation can be a symptom of depression [10].

During the early developmental stages of life, individuals experience a collection of negative life events, such as parental neglect, war, bullying, dysfunctional home, sexual abuse, and economic deprivation, which are known as childhood adversities [11]. [12], reported in a study on childhood adversity and suicidal ideation in a Clinical Military Sample that suicidal ideation was higher among those that had experienced adversity during childhood.

Economic crises have also been linked to an increase in suicidal ideation [13]. Economic recession brings with it a lot of challenges, which might hinder students from accessing their basic needs, leading to financial difficulty with paying school fees and accessing academic materials.

[14] suggests an association between economic factors and suicidal ideation among youth in Eastern Mediterranean Region. Also, suicidal ideation can be associated with the publication of suicide; in essence, the manner of media reporting can make others to start having copycat suicidal thoughts $[15,16]$.

Despite the rise in suicidal ideation rate among Nigerian students, research is scarce on gender reporting of suicide ideation and psychosocial risk, hence the need for this research. The following Hypotheses were raised:

1. There will be no significant relationship between gender, depression, and suicidal ideation.

2. There will be no significant relationship between gender, childhood adversity, and suicidal ideation.

3. There will be no significant relationship between gender, economic recession, and suicidal ideation.

4. There will be no significant relationship between gender, media reporting, and suicidal ideation.

\section{Methodology}

\section{Research Design}

This is quantitative research, the research design adopted for the study is the descriptive survey design of the ex-post facto type.

\section{Population of the Study}

The populations for the study comprised of all undergraduate students at universities located in Ogun State.

\section{Study Area}

This study was conducted in two universities in Nigeria among undergraduate students.

\section{Sample Size and Sampling Technique}

The sample size for the study was 993 . The sampling technique was multi-Stage. The stratified sampling technique was employed at Stage 1, and this involved dividing the universities into strata- public universities and private universities and randomly selecting two universities a private and public. In Stage 2, simple random sampling was used for the selection of respondents (undergraduates) from the two universities.

\section{Research Instrument}

The instrument used for the execution of this study was a questionnaire titled "Suicidal Behaviour Continuum and Gender-Based Interactive Influence of Psychosocial Risk Factors". The questionnaire was based on both validated and structured researcher questions. There were three major sections. Section A was on sociodemographic characteristics, Section "B" addressed the psychosocial factors and had four main aspects, the questions were adapted from the validated questionnaire, and some were fully structured by the researchersquestions eliciting information on depression were adapted from Beck's Depression Inventory, for childhood adversity it was adapted from WHO's "Adverse Childhood Experiences International Questionnaire" while 
questions on economic recession and media reporting were structured by the researcher.

All questions in Section B" were on a fivepoint Likert Scale, ranging from strongly agree, agree, neither agree nor disagree, disagree and strongly disagree. Section C" was an adapted version of Oman, Bagge, Guitterrey, Konick, Kooper, and Barrios (2001) Suicide Behaviour Questionnaire-Revised (SBQ-R).

\section{Method of Data Collection}

The questionnaire was administered physically by the researcher to the respondents. They were informed of the purpose and assured of confidentiality. Also, verbal consent was gotten from them before been given a questionnaire to fill. The researcher also informed them of their right to pull out of completing the filling if at any point they were uncomfortable.

\section{Ethical Consideration}

Permission was obtained from the universities to carry out the research. Also, consent of the respondents was sought, and the data received was treated with confidentiality. Also, no respondent was mandated to take part.

\section{Data Analysis}

The data were analyzed using Pearson Moment Correlation Matrix. A correlation analysis was conducted between variables of interest to determine the significant relationship that exist.

\section{Results}

Table 1 reveals the correlation analysis of the relationship between gender, depression, and suicidal ideation among undergraduate students in Ogun State, Nigeria. The result shows that gender is negatively and significantly correlated to depression $r=-.074$, $\mathrm{p}>0.05$ ), while gender is positively and significantly correlated to suicidal ideation $(\mathrm{r}=$ $.129, \mathrm{p}>0.01)$. Depression is negatively and significantly correlated to suicidal ideation $(\mathrm{r}=$ $-.242, \mathrm{p}>0.01$ ). Hence the null hypothesis of no significant relationship between gender, depression, and suicidal ideation is hereby discarded, and the alternate hypothesis is accepted that there is a significant relationship.

$\mathrm{H}_{2}$ There will be no significant relationship between gender, childhood adversity, and suicidal ideation.

Table 1. Showing the Pearson product Moment Correlation of Gender on Depression and Suicidal Ideation

\begin{tabular}{|l|l|l|l|l|}
\hline \multicolumn{2}{|l}{ Correlations } & Gender & Depress & Suicidal Ideation \\
\hline \multirow{5}{*}{ Gender } & Pearson Correlation & 1 & $-.074^{*}$ & $.129^{* *}$ \\
\cline { 2 - 5 } & Sig. (2-tailed) & & .023 & .000 \\
\cline { 2 - 5 } & $\mathrm{N}$ & 952 & 944 & 936 \\
\hline \multirow{5}{*}{ Suicidal Ideation } & Pearson Correlation & $-.074^{*}$ & 1 & $-.242^{* *}$ \\
\cline { 2 - 5 } & Sig. (2-tailed) & .023 & & .000 \\
\cline { 2 - 5 } & $\mathrm{N}$ & 944 & 982 & 973 \\
\hline & Pearson Correlation & $.129^{* *}$ & $-.242^{* *}$ & 1 \\
\cline { 2 - 5 } & Sig. (2-tailed) & .000 & .000 & \\
\cline { 2 - 5 } & $\mathrm{N}$ & 936 & 973 & 974 \\
\hline$*$ Correlation is significant at the 0.05 level (2-tailed). \\
\hline \multirow{2}{*}{$* *$ Correlation is significant at the 0.01 level (2-tailed). } \\
\hline
\end{tabular}

Table 2 reveals the correlation analysis of the relationship between gender, childhood adversity, and suicidal ideation among undergraduate students in Ogun State, Nigeria.
The result shows that gender is positively and significantly correlated to suicidal ideation $(\mathrm{F}=-$ $.129, \mathrm{p}>0.01)$. 
Suicide ideation is negatively and significantly correlated to childhood adversity $(\mathrm{F}=-.149, \mathrm{p}>0.01)$. Hence the null hypothesis of no significant relationship between gender, depression, and suicidal ideation is hereby discarded, and the alternate hypothesis is accepted that there is a significant relationship.

$\mathrm{H}_{3}$ There will be no significant relationship between gender, economic recession, and suicidal ideation.

Table 2. Showing the Pearson Product Moment Correlation of Gender on Childhood Adversity and Suicidal Ideation

\begin{tabular}{|l|l|l|l|l|}
\hline \multicolumn{2}{|l|}{ Correlations } & Gender & Suicidal Ideation & Childhood Adversity \\
\hline \multirow{4}{*}{ Gender } & Pearson Correlation & 1 & $.129^{* *}$ & -.025 \\
\cline { 2 - 5 } & Sig. (2-tailed) & & .000 & .437 \\
\cline { 2 - 5 } & $\mathrm{N}$ & 952 & 936 & 950 \\
\hline \multirow{4}{*}{ Suicidal ideation } & Pearson Correlation & $.129^{* *}$ & 1 & $-.149^{* *}$ \\
\cline { 2 - 5 } & Sig. (2-tailed) & .000 & & .000 \\
\cline { 2 - 5 } & $\mathrm{N}$ & 936 & 974 & 972 \\
\hline \multirow{3}{*}{ Childhood Adversity } & Pearson Correlation & -.025 & $-.149^{* *}$ & 1 \\
\cline { 2 - 5 } & Sig. (2-tailed) & .437 & .000 & \\
\cline { 2 - 5 } & $\mathrm{N}$ & 950 & 972 & 990 \\
\hline \multirow{2}{*}{$* *$ Correlation is significant at the 0.01 level (2-tailed). } & \\
\hline
\end{tabular}

Table 3 reveals the correlation analysis of the relationship between gender, economic recession, and suicidal ideation among undergraduate students in Ogun State, Nigeria. The result shows that gender is positively and significantly correlated to suicidal ideation $(\mathrm{F}=$ $-.129, \mathrm{p}>0.01)$, while gender is negatively and significantly correlated to Economic recession $(\mathrm{F}=-.109, \mathrm{p}>0.01)$. Economic recession is negatively and significantly correlated to suicidal ideation $(F=-.129, p>0.01)$. Hence the null hypothesis of no significant relationship between gender, depression, and suicidal ideation is hereby discarded, and alternate hypothesis is accepted that there is a significant relationship. $\mathrm{H}_{4}$ There will be no significant relationship between gender, suicidal ideation, and media reporting.

Table 3. Showing the Pearson Product Moment Correlation of Gender on Economic Recession and Suicidal Ideation

\begin{tabular}{|l|l|l|l|l|}
\hline \multicolumn{2}{|l}{ Correlations } & Gender & Suicidal ideation & EcoRec \\
\hline \multirow{4}{*}{ Gender } & Pearson Correlation & 1 & $.129^{* *}$ & $-.109^{* *}$ \\
\cline { 2 - 5 } & Sig. (2-tailed) & & .000 & .001 \\
\cline { 2 - 5 } & $\mathrm{N}$ & 952 & 936 & 949 \\
\hline \multirow{4}{*}{ Euicidal Ideation } & Pearson Correlation & $.129^{* *}$ & 1 & $-.129^{* *}$ \\
\cline { 2 - 5 } & Sig. (2-tailed) & .000 & & .000 \\
\cline { 2 - 5 } & $\mathrm{N}$ & 936 & 974 & 970 \\
\hline \multirow{3}{*}{$* *$ Conomic Recession } & Pearson Correlation & $-.109^{* *}$ & $-.129^{* *}$ & 1 \\
\cline { 2 - 5 } & Sig. (2-tailed) & .001 & .000 & 988 \\
\cline { 2 - 5 } & $\mathrm{N}$ & 949 & 970 & \\
\hline
\end{tabular}

The Table 4 reveals the correlation analysis of relationship between gender, suicide ideation and media reporting among undergraduate student in Ogun State, Nigeria. The result shows that gender is positively and significantly correlated to suicidal ideation $(\mathrm{r}=-.129$, $\mathrm{p}>0.01$ ), and gender is negatively and significantly correlated to media reporting $(r=$ - 
087, $\mathrm{p}>0.01$. Hence the null hypothesis of no significant relationship between gender, suicidal ideation and media reporting is hereby discarded and alternate hypothesis is accepted, that there is a significant relationship.

Table 4. Showing the Pearson Product Moment Correlation of Gender on Media Reporting and Suicidal Ideation

\begin{tabular}{|c|c|c|c|c|}
\hline \multicolumn{2}{|l|}{ Correlations } & Gender & Suicide Ideation & Media Reporting \\
\hline \multirow[t]{3}{*}{ Gender } & Pearson Correlation & 1 & $.082^{*}$ & $-.087^{* *}$ \\
\hline & Sig. (2-tailed) & & .011 & .006 \\
\hline & $\mathrm{N}$ & 989 & 971 & 989 \\
\hline \multirow[t]{3}{*}{ Suicide Ideation } & Pearson Correlation & $.082^{*}$ & 1 & -.024 \\
\hline & Sig. (2-tailed) & .011 & & .448 \\
\hline & $\mathrm{N}$ & 971 & 974 & 974 \\
\hline \multirow[t]{3}{*}{ Media Reporting } & Pearson Correlation & $-.087^{* *}$ & -.024 & 1 \\
\hline & Sig. (2-tailed) & .006 & .448 & \\
\hline & $\mathrm{N}$ & 989 & 974 & 992 \\
\hline \multicolumn{5}{|c|}{ *. Correlation is significant at the 0.05 level (2-tailed). } \\
\hline \multicolumn{5}{|c|}{ **. Correlation is significant at the 0.01 level (2-tailed). } \\
\hline
\end{tabular}

\section{Discussion}

The result of hypothesis one shows that there is a significant relationship between gender, depression, suicidal ideation. The result shows that gender is negatively and significantly correlated to depression, with the male more significantly affected by depression. This is in tandem with a study by [17] which reported that different degrees of depression were more prevalent with male college students than the female.

Also, hypothesis one showed a significant and positive correlation between gender and suicidal ideation, with a significant prevalence of suicidal ideation among females. Though male showed a higher prevalence of depression, however, the female seems to be significantly correlated with suicidal ideation, which aligns with [18] research that identified a high prevalence of depression among men and suicidal ideation among women.

Hypothesis two shows a significant relationship between gender, childhood adversity, and suicidal ideation. The result reveals a significant relationship between gender, suicidal ideation, and childhood adversity. Childhood adversity occurring more among the male, while female showed a significant prevalence of suicidal ideation. This, however, negates the findings of [19], which assert that youth with adverse childhood adversity had a greater probability of suicidal ideation.

In hypothesis three, a significant relationship is revealed between gender, economic recession, and suicidal ideation. It shows gender has been correlated to suicidal ideation, with the female having higher incidences of suicidal ideation. [20] On the other hand reports, suicidal ideation has been of a greater occurrence among males. Hypothesis three also posits that there is a correlation between gender and economic recession. This can be attributed to the fact that men are always at the receiving end of the major impact of employment loss in times of recession [21].

Hypothesis four shows a significant relationship between gender, media reporting, and suicidal ideation. Females have a significant occurrence of been influenced by media reporting and a higher probability of suicide ideation. Research has shown an increase in the number of suicides after a reporting of celebrity suicide [22]. 


\section{Conclusion}

The study has shown that gender has a significant impact on incidences of suicide ideation and its psychosocial risk factors.

\section{Recommendations}

From the findings of this research, the following recommendations were made.

1. Creation of awareness on the effect of childhood experience on latter psychological health of a person.

2. Government should also bring to pass the "Social Work Bill of Professionalism" in Nigeria. This will empower the social workers in implementing the Nigerian

\section{References}

[1] Omigbodun, O., Dogra, N., Esan, O., \& Adedokun, B. (2008). Prevalence and correlates of suicidal behaviour among students in Southwest Nigeria. International Journal of Social Psychiatry, 54(1), $34-46$.

[2] Korb I, Plattner, I. E. (2014). Suicide ideation and depression in university students in Botswana. $J$ Psychol Afr. 24(5):420-6.

[3] Arria AM, O'Grady KE, Caldeira KM, Vincent KB, Wilcox HC, Wish ED. (2009) Suicide ideation among college students: a multivariate analysis. Arch Suicide Res. ;13(3):230-46.

[4] Centers for Disease Control and Prevention (CDC). (2010). Web-based Injury Statistics Query and Reporting System (WISQARS) [Online]. National Center for Injury Prevention and Control, CDC (producer). Available from URL: www.cdc.gov/injury/wisqars/index.html.

[5] Joe S, Stein DJ, Seedat S. (2008). Non-fatal suicide behaviour among South Africans. Social Psychiatry \& Psychiatric Epidemiology; 43:454461.

[6] Abdollahi Abbas, Mansor Abu Talib, Siti nor Yaacob, and Zanariah Ismail. (2015). "The 5t; rtRole of Hardiness in Decreasing Stress and Suicidal Ideation in a Sample of Undergraduate Students." Journal of Humanistic Psychology 55(2): 202-22.
"Child Right Act" and reduction of childhood adversity.

3. Establishment of student support centers in all schools to provide hands-on therapeutic services to students with psychosocial issues.

\section{Acknowledgement}

The researcher would like to thank the respondents for their participation and the two institutions where the study was conducted.

\section{Conflict of Interest}

The authors declare that there is no conflict of interest.

http://search.proquest.com.proxy.lib.pdx.edu/psycinf o/docview/1666306951/AB558F8F76314208PQ/15? accountid=13265 (March 26, 2015).

[7] Whitlock, J., \& Knox, K. (2007). The relationship between self-injurious behavior and suicide in a young adult population. Archive of Pediatric Adolescence Medical, 161(7), 634-640.

[8] Mackenzie, S. Wiegel, J., Mundt, M., Brown, D., Saewyc, E., Heiligenstei, Harahan, B., \& Fleming, M. (2011). Depression and suicide ideation among students accessing campus healthcare. American Journal of Orthopsychiatry, 81(1), 101-107.

[9] Cash SJ, Bridge JA. (2009). Epidemiology of youth suicide and suicidal behavior. Curr Opin Pediatr. 21(5):613-9.

[10]Centers for Disease Control and Prevention (CDC). (2013) Web-based Injury Statistics Query and Reporting System (WISQARS) [Online]. (2013, 2011) National Center for Injury Prevention and Control, CDC (producer). Available from http://www.cdc.gov/injury/wisqars/index.html.

[11] Coêlho BM, Andrade LH, Borges G, Santana GL, Viana MC, Wang Y. P. (2016). Do Childhood Adversities Predict Suicidality? Findings from the General Population of the Metropolitan Area of São Paulo, Brazil. Plos One 11(5): e0155639. doi: 10.1371/journal.pone.0155639.

[12] Skopp N.A., Luxton, D.D., Bush, N., \& Sirotin A. (2011). Childhood Adversity and Suicidal 
Ideation in a Clinical Military Sample: Military Unit Cohesion and Intimate Relationships as Protective Factors. Journal of Social and Clinical Psychology, Vol.30 Iss. 4.

[13] Economou, M., Madianos, M., Peppou, L.E., Theleritis C., Patelakis A., and Stefanis C. (2013). Suicidal ideation and reported suicide attempts in Greece during the economic crisis. World Psychiatry; 12:53-59.

[14] Khalid Rabia (2012). "Suicide Ideation and Its Associated Risk Factors among Adolescent Students in the Eastern Mediterranean Region". Thesis, Georgia State University, 2012. https://scholarworks.gsu.edu/iph_theses/237.

[15] Sisask, M., \& Värnik, A. (2012). Media roles in suicide prevention: a systematic review. International journal of environmental research and public health, 9(1), 123-138. https://doi.org/10.3390/ijerph9010123.

[16] Yoshioka, E., Hanley, S. J. B., Kawanishi, Y., \& Saijo, Y. (2014). The epidemic of charcoal burning suicide in Japan. The British Journal of Psychiatry, 204(4), 274-282. https://doi.org/10.1192/bjp.bp.113.135392.

[17]Gao, Wenjuan \& Ping, Siqing \& Liu, Xinqiao. (2019). Gender differences in depression, anxiety, and stress among college students: A longitudinal study from China. Journal of Affective Disorders. 263. 10.1016/j.jad.2019.11.121.
[18] Villanueva P, Arteaga A, Fernández-Montalvo J., (2019). Gender Differences in Risk Factors Related to Suicidal Ideation Among Callers to Telephone Helplines in Spain. Arch Suicide Res. 23(4):605-615. doi: 10.1080/13811118.2018.1480987.

[19] Kappel R.H., Livingston M.D., Patel S.N., Villaveces A., Massetti GM. (2021). Prevalence of Adverse Childhood Experiences (ACEs) and associated health risks and risk behaviors among young women and men in Honduras. Child Abuse Negl.;115:104993. doi: 10.1016/j.chiabu.2021.104993. Epub 2021 Feb 19. PMID: 33611130; PMCID: PMC8136622.

[20] Ibrahim N, Amit N, Che Din N, Ong HC. (2017). Gender differences and psychological factors associated with suicidal ideation among youth in Malaysia. Psychol Res Behav Manag; 10:129-135. doi: 10.2147/PRBM.S125176. PMID: 28496374 ; PMCID: PMC5417667.

[21] Engemann, K.M. \& Wall, Howard. (2010). The effects of recession across demographic groups. Federal Reserve Bank of St. Louis Review. 92. 1-26. [22] Niederkrotenthaler T, Braun M, Pirkis J, Till B, Stack S, Sinyor M et al. (2020). Association between suicide reporting in the media and suicide: systematic review and meta-analysis BMJ 2020; 368: m575 doi:10.1136/bmj.m575. 